\title{
Innovative Fluid Machine that Can Operate both as a Turbine and as a Pump
}

\section{Stefano Farné}

Department of Industrial, Electrical, Computer and Biomedical Engineering, University of Pavia, Italy. DOI: http://doi.org/10.38177/ajast.2020.4405

Copyright: (2020 Stefano Farné. This is an open access article distributed under the terms of the Creative Commons Attribution License, which permits unrestricted use, distribution, and reproduction in any medium, provided the original author and source are credited.

\section{ABSTRACT}

The Integrated turbine electric generator (ITEG) machine has been designed by Stefano Farné and Vito Lavanga and it is the subject of a registered patent that has also received WIPO positive research reports. ITEG allows to integrate a fluid dynamic machine and an electric motor into a single device, making it versatile and allowing a wide range of use both as a pump, giving prevalence to a fluid, and as a turbine, generating electric power Thanks to the extreme simplicity of installation and to the low maintenance request, since it is gearless, ITEG can be more convenient than traditional machines, both for hydroelectric energy production and for pumping purposes. The present paper shows the various aspects of the design of this innovative machine, presents the literature review examined in terms of scientific articles and patents and illustrates the mathematical model that allows ITEG sizing and the simulation of its operation.

Keywords: Fluid machines, Rotor, Stator, Turbine, Pump, Generator, Engine.

\section{Introduction}

The transformation of the energy of a moving fluid into electric energy is normally obtained through a hydraulic turbine (eg. Pelton, Francis, Kaplan, propeller) being keyed on a connected shaft directly or indirectly to the rotor of an electric generator. The presence, in the actual machines, of intermediate mechanical elements and related frictions and / or inertias, determines hydraulic, volumetric and mechanical losses, with consequent reductions in the efficiency of the transformation itself. Moreover, it obliges two design and distinct productions (turbine and generator) and their interfacing, with consequent higher capex and opex costs. In many cases compact objects are found which, supported by joint structures, integrate turbine and generator functions sharing an axis at best, but always insisting on different sections of the axis itself, not always in alignment. In the opposite case, that is the transformation of the electric energy in the movement of a fluid, it is currently carried out through the use of two separate machines that is an electric motor which drives a pump, with the same disadvantages of the previous case. On the contrary, ITEG consists of a system that integrates the mobile component - rotor - with the fixed component - stator - in a single assembly, as better described in the following section.

\section{Materials and Methods}

ITEG is essentially composed of rotor and stator components, both for engine/pump and for generator/turbine set-ups, immersed in separate environments and are described with reference to the figures:

\section{- 1 of a split section}

\section{- 2 of a cross section to the rotation axis}

which show the device details with numbers in brackets. The device (1) essentially comprises a first part or rotor system (2) and a second part or stator system (10), and is applied to a conduit (11) flowed by a fluid in such a way that the stator part (10) is external and the rotor part (2) is internal to (11). The material of which the conduit (11) is 
constituted is magneto-transparent so as not to hinder the interaction by magnetic induction between the rotor part (2) and the stator part (10) of the device (1). The rotor (2) consists of three concentric cylinders:

- an external cylinder (3), including permanent magnets, designed to fulfill the role of generator / electric motor, interacting with said second stator part (10);

- an intermediate cylinder (4), structured with a bundle of ducts (7), wound with a helix shape, inside which the fluid passes;

- an internal cylinder (5) designed to perform the rotation axis function (6) of the rotor system (2).

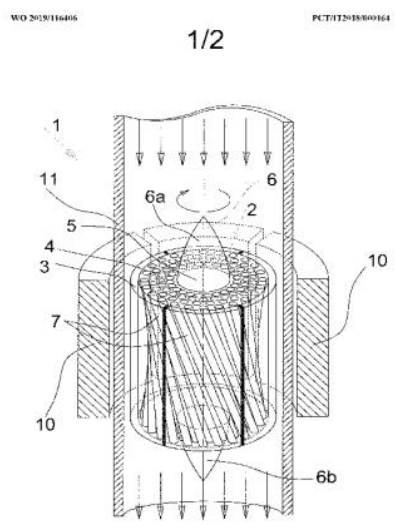

Fig. 1

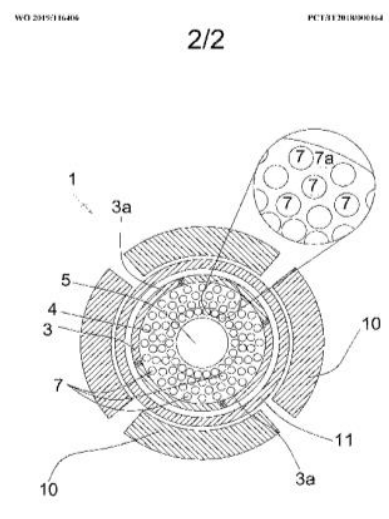

Fig. 2

The rotor (2) carries out the turbine/pump functions in a single element and interacts, by its peripheral part (3), with the stator (10), that performs the generator / engine functions. The innermost cylinder (5) is completed, both at the head and in the tail, by ogives (6a, 6b), preferably of a conical shape, suitable and functional to the dynamics of the fluid flows and their characteristics. If the device (1) is arranged with the axis (6) in a vertical position, the inner cylinder (5) can be conveniently ballasted, or lightened (filled with air); in this way, the thrust of Archimedes can contribute to counteract the axial forces to which the rotor system (2) is subjected, as discussed in the Results and Discussion section. If the intermediate cylinder (4) is hit by a fluid flow parallel to (5), is rotated, while, if it is put in rotation, it imparts a longitudinal flow to the fluid. In the first case the intermediate cylinder (4) fulfills the role of turbine, while in the second case it performs the role of a pump. The ducts (7) have sections designed to maximize the mechanical energy exchange between the fluid and the rotor system (2), limiting the negative effects of turbulence. In order to maximize the flow passage section, the ducts (7) have very low thicknesses with respect to the useful working section. The sections of said ducts (7) can be of circular, elliptic or polygonal, depending on the type of flow and the purposes assigned to the machine. In any case, the interstices (7a) should be kept to a minimum. The dimensions of the pitch and radius of development of the ducts (7) winding must be chosen according to the nature of the fluid in which the rotor system (2) is immersed. The outermost cylinder (3) includes one or more pairs of permanent magnets (3a), having the shape of circular crown sections and constituting the outer surface of the rotor system (2). The stator system (10) is suitable for generating / inducing electromagnetic fields which interact with the permanent magnets (3a) present in the rotor system (2). The electromagnetic fields are generated / induced by windings (not shown in the figures 1,2) wound in the stator slots. In the case where a 
suitable tension is applied to the stator windings, the interaction with the permanent magnets (3a) of the rotor (2) will cause its rotation and the device (1) works as a pump, causing the flow of fluid present in the duct (11). In the event that the flow of the fluid present in the duct (11) causes the rotation of the rotor (2), the interaction between its permanent magnets (3a) and the windings present in the stator (10) generates an electromotive force in said windings and the device (1) functions as a generator. The device (1) according can be used also independently of the presence of the conduit / pipe (11), for example in air or free water.

The rotor cylinder (2) can be produced by extrusion processes, either with metallic or polymeric materials, chosen according to the intended use; in particular, in the case of complex geometries, it can be realized by 3D printing.
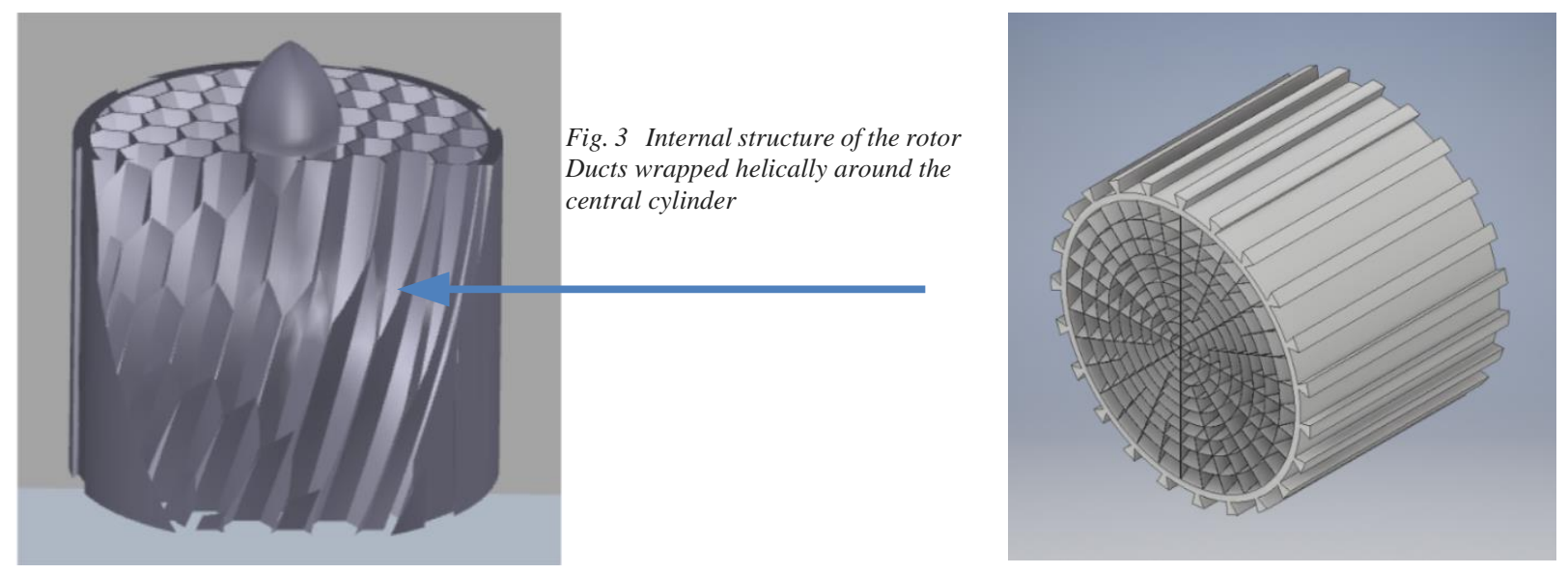

Fig. 4 Perspective view of the rotor

The rotor ducts have sections aimed at maximizing the energy exchange with the fluid and the rotor; their pitch and the radius of development of the winding propeller will be functional depending on the nature of the fluid (density, viscosity, molecular structures, ...) and on fluid dynamic structures in which it is assumed to operate (figg. 3 and 4). The third outermost cylinder contains a plurality of polar pairs, generated by permanent magnets, in the form of circular crown sections shaped like an omega or a dovetail (fig. 5) and embedded in the support material to better withstand centrifugal forces and instability. The fixing can be completed with adhesives, glue, resins or other adhesives depending on the use of ITEG and the fluid with which it works, to prevent the magnet from axially slipping out of its housing. The rotor cylinder (Fig. 6) is housed inside a stator cylinder, solidly anchored to the operating environment, and consisting of magnetic sheets (Fig. 7) and electrical windings (Fig. 8) capable of generating or inducing an electromagnetic field, concatenated with that of the rotor, according to the known laws of electromagnetic induction.

In operation as a turbine, the fluid current hits the rotor and, penetrating inside the ducts of the intermediate cylinder, gives a thrust action on the inclined walls of the ducts, imparting a rotational movement (fig. 9 and 10). The mechanical energy thus generated allows the permanent magnets, located in the external areas of the rotor, to generate a variable magnetic field and therefore to induce an electromotive force in the stator windings. Using ITEG in alternating mode, an inverter will follow, which will bring the frequency of the current to the frequency required by the grid. This transition between rectifier and inverter is necessary because the turbine will not turn at constant speed and exactly at 50 or $60 \mathrm{~Hz}$. 


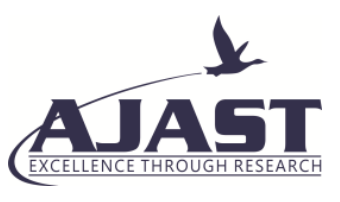

Asian Journal of Applied Science and Technology

Volume 4, Issue 4, Pages 44-67, October-December 2020

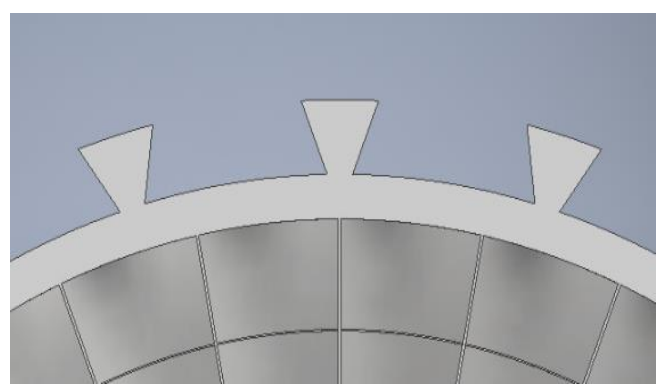

Fig. 5 Dovetails to accommodate permanent magnets

In operation as a pump, by feeding the stator windings with an appropriate electromotive force, the electromagnetic field thus generated interacts with that of the permanent magnets of the rotor, putting it in rotation. The useful surface of the rotor covers an extremely important part of the ITEG as it exploits the most part of the surface affected by the fluid which will move the rotor to produce electric power or, in the case it is used as a pump, it will move the fluid in a given direction. This feature makes ITEG very functional and efficient.

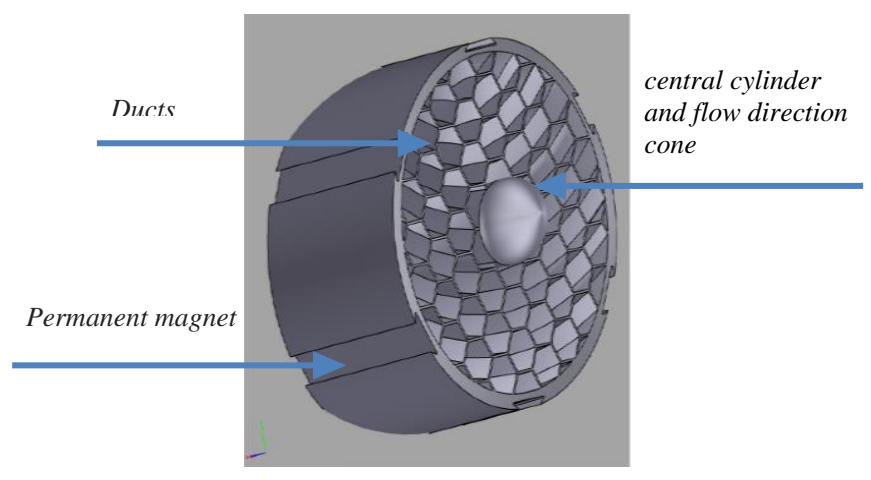

Fig. 6 Structure of the rotor

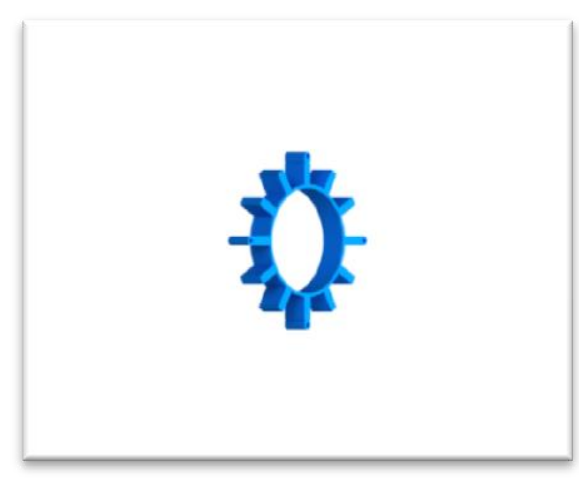

Fig. 7 Magnetic sheet pack

The impact surface is a hive of geometric shapes (identical or different from each other) and is obtained on the entire circle that comes into contact with the fluid, making almost all of the surface capable of producing work (part of the surface is dedicated to the separation walls). The hole of the duct can have any geometric shape (circles, squares, hexagons, triangles, etc.) as the work produced does not depend on the geometric shape of the surface but on their distribution on the useful area of the rotor, which therefore can be optimized in the best possible way.

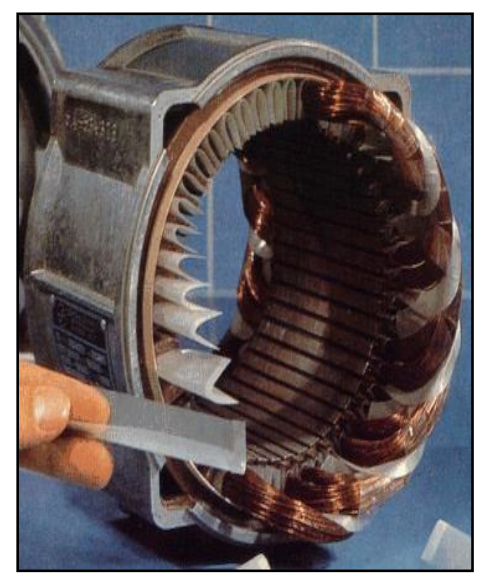

Fig. 8 Electrical windings 


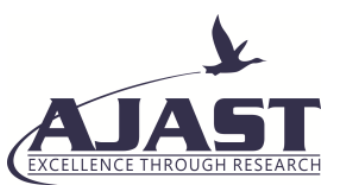

Asian Journal of Applied Science and Technology Volume 4, Issue 4, Pages 44-67, October-December 2020

The cone-shaped part directs the flow of the fluid inside the ducts that fill up and the reaction of the forces between the moving fluid and the walls of the enveloping ducts generates rotation. The profile of the section of the rotor allows to decrease the weight and to reduce the size of the interstices between a duct and the adjacent ones, increasing its efficiency, since it intercepts the fluid more effectively. Furthermore, since there are no mechanical fasteners and fixing, the losses due to the friction are reduced, significantly improving the performance of ITEG compared to other fluid machines. The rotor is kept in axis by the magnets located on its external surface, which interact with the electromagnetic stator.

The longitudinal position of the axis is maintained by magnetic bearings consisting of toroids in permanent magnets at the ends, suitably sized and magnetized. The functioning of the magnetic bearings is based on the repulsive thrust that is generated when the north pole and south pole of a magnet are placed close together. When the rotor tends to come out of the stator position, the magnetic bearings placed on the case (fig. 11) will tend to push it in the opposite direction of translation, preventing it from coming out of its seat. Similarly, the crown placed at the opposite end of the case will act in the same way by keeping the rotor in a "magnetic cage". In this way, the magnetic bearings interact with the permanent magnets placed on the rotor. A thickness between the rotor and stator is present, to avoid possible collisions during exercise and therefore slowdowns or sudden stops. A schematic installation of ITEG is shown in fig. 12.

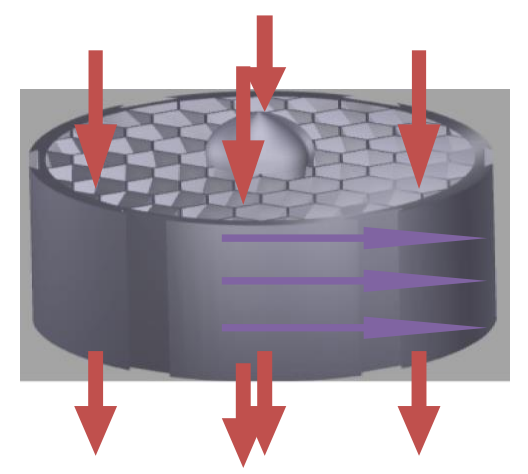

Fig. 9 ITEG flowed by the fluid (vertical vectors)

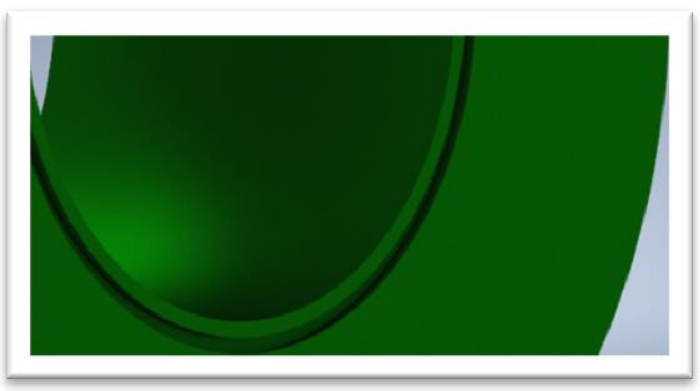

Fig.11 Housing of the magnetic bearing inside the case

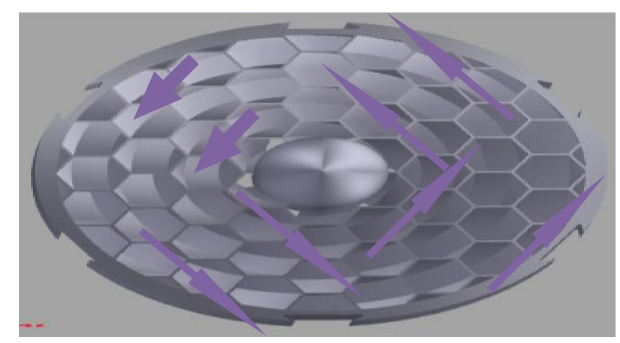

Fig. 10 Forces represented on the plane

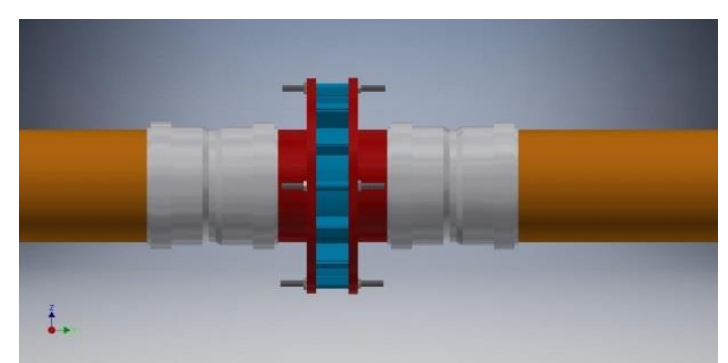

Fig. 12 ITEG possible installation

\section{Literature and Patents Review}

As illustrated below, ITEG can be considered an evolution of the Archimedes' screw or cochlea. The literature review did not highlight systems equal to ITEG, therefore the search of scientific papers and of patents has been 


\section{A 1 A ST}

Asian Journal of Applied Science and Technology Volume 4, Issue 4, Pages 44-67, October-December 2020

focused on Archimedes screw-based systems. Stergiopoulou et al. in several journal articles [1-6] and Conference Proceedings [19-31] present various applications of Archimedean Screws as turbine in hydro-electric power generators using both sea and rivers. Casini [7] presents an application of the harvesting energy from in-pipe hydro systems at urban and building scale by providing a consistent amount of clean and continuous energy without the typical intermittency of wind and solar and at the same time helping in pipelines management and maintenance.

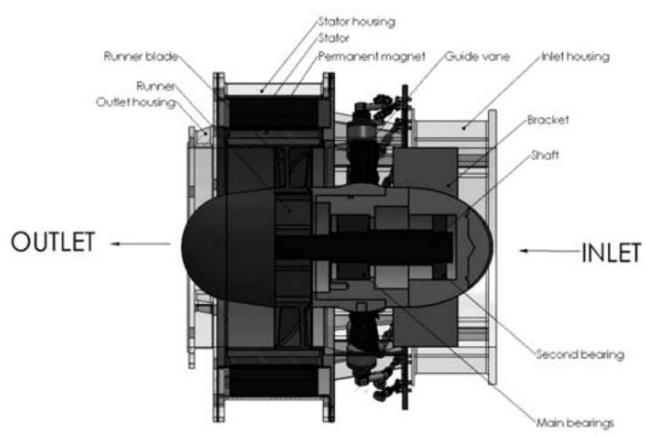

Fig. 13 Integrated turbine with a generator

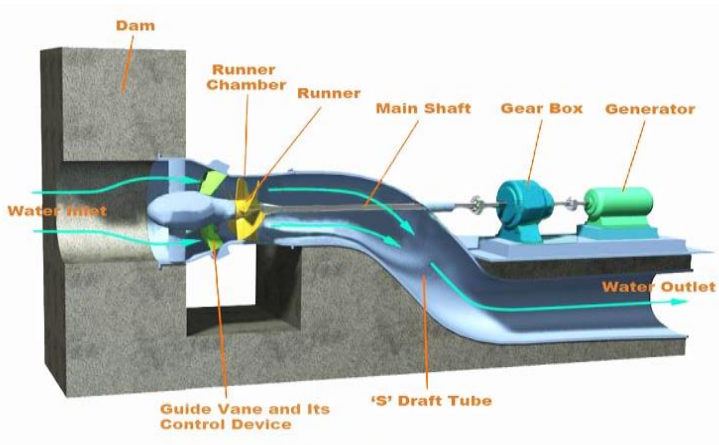

Tubular Turbine ('S'Type)

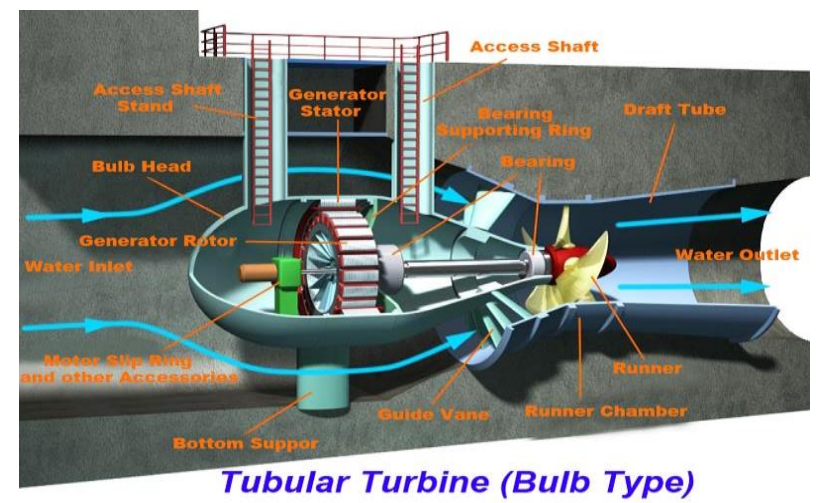

Fig. 15 Tubular turbine with internal generator

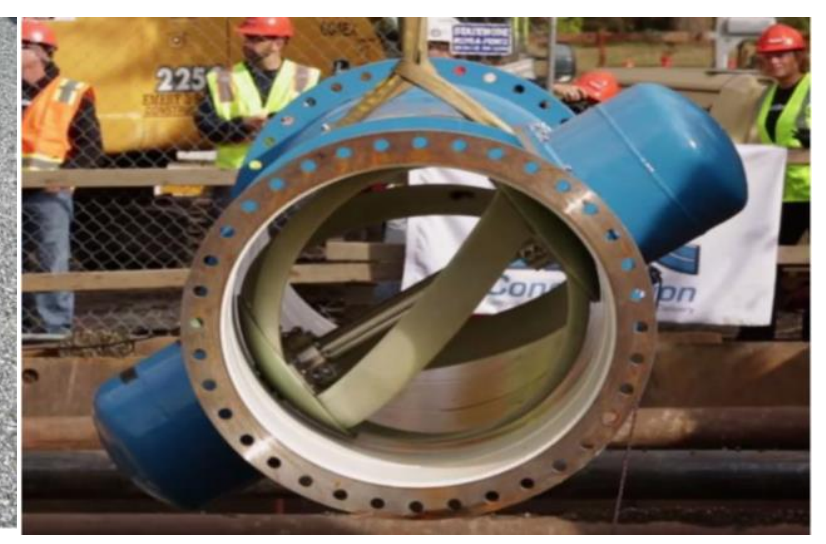

Fig. 17 Gorlov spherical turbine
Fig. 16 Hydrocoil 600 auger turbine

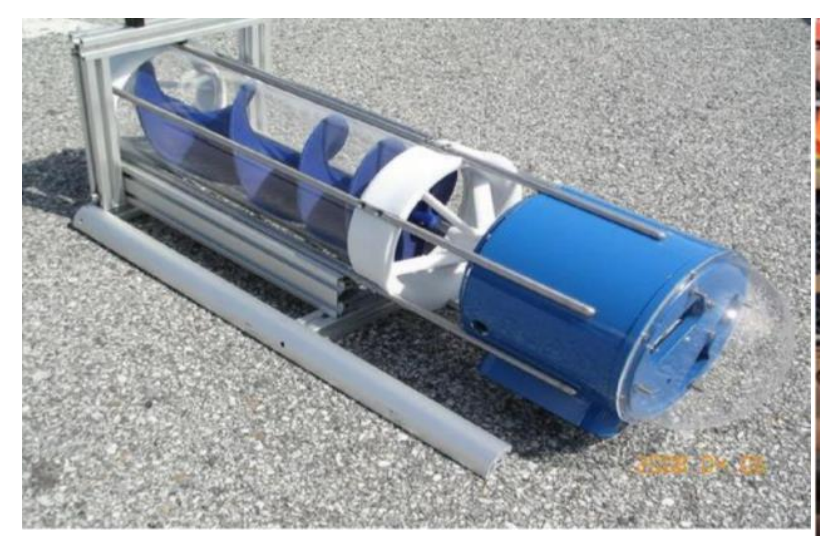

This system allows to keep the input speed in the impeller constant as the flow rate varies and therefore to keep the hydraulic load available at the input almost constant. It should be noted that in ITEG the section is fully engaged in 
intercepting the fluid and does not require tools to regulate the flow. Many other journal articles [from 9 to 14], books [from 19 to 21] and Conference Proceedings [from 34-37] have been consulted on how to design Archimedes' screws, but did not find devices really similar to ITEG. A special mention deserves the article of Sobczyk T. et al. [15], which presents an integrated turbine with a generator for small hydro-power plants. This study of the Polytechnic University of Krakow has been conducted on a Kaplan type turbine integrated with a permanent magnet generator (fig. 13) through the fixing of magnets on the ends of the blades.

By experiments, in which Sobczyk T. et al. tested the power delivered as a function of the flow rate and the available jump, it has been appreciated the remarkable efficiency of this type of system, both as regards the power output values and the minimal maintenance request necessary to keep the micro system operational. The turbine operates at variable speed and therefore the generator produces voltages at variable magnitude and frequency. For that reason, the generated energy should be converted by a power electronics unit to fit the parameters of the external grid.

The applications of the above mentioned papers, are the integrated systems in pipelines used for the production of hydroelectric energy which, for dimensional reasons, in almost all cases do not exceed $100 \mathrm{~kW}$ and therefore are defined as "small hydropower system" (as established by the Directive 2004/101/EC of the European Parliament which includes plants that produce less than $20 \mathrm{MW}$ of power). Integrated systems in the ducts are: tubular turbines (fig. 14) if the generator is external to the duct or (fig. 15) if the generator is also inserted in the duct called in this case a bulb due to the particular shape of the watertight container of the generator), Archimedean screw or auger turbines (fig. 16) which in the specific case of the figure has a progressive number of windings per axial movement unit in order to increase their efficiency due to the decrease in speed of the fluid to travel it (an aspect that could also affect the windings of the ITEG), or the spherical turbines with vertical axis designed by Alexander Gorlov (fig. 17) which can be found applied inside the city drain pipes such as, for example, in the city of Riverside in California. In all these cases the turbine transmits the rotary motion to the rotor by means of belts or shafts etc. ... which further presuppose the presence of bearings that have a limited life and represent a loss of energy due to friction.

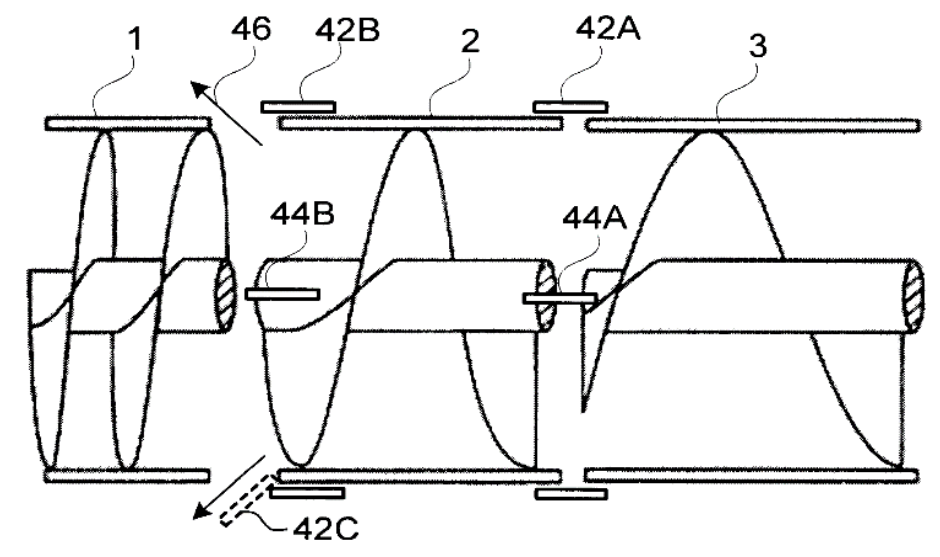

Fig. 18 Ribbon drive power generation patent US6626638

On the contrary, ITEG does not require the presence of transmission parts between the fluid dynamic machine and the electric machine, thus guaranteeing increased mechanical efficiency and a significant lower maintenance 
request. In the present study, several patents have been examined and, in the following, some of them, which present analogies with ITEG, are illustrated. The most similar example, in terms of shape and principle of operation, to the turbine used in the ITEG system among those mentioned above, is the turbine named Hydro coil 600 and shown in fig. 16; it has a screw by means of which the fluid dynamic energy is transformed into rotational mechanical energy. The patent US6626638 [39] of Jonathan B. Rosefsky (fig. 18) concerns a device for producing hydroelectric power using a ribbon drive electrical power generator with flow handling improvements related to self-orientation and staged start-up. The key element of this question is that there is a change in the frequency of the curves of the belt-shaped drive, which proceeds from a low frequency (a few windings per unit of length) in the initial portion of the apparatus at a high frequency (many windings per unit of length) in the rear part of the apparatus.

The object resembles a corkscrew but has a decreasing winding frequency proceeding along the length of the central axis. The speed of the fluid is directly proportional to the pitch of the windings (i.e. the angle of inclination of them) and to the rotation speed of the turbine $(v=p \omega)$; therefore if it is desired to keep constant or increase $\omega$, the decrease in $v$ must correspond to at least an equal decrease in the pitch $\mathrm{p}$. The reduction in the axial speed of the water is a consequence of the transfer of energy from the water to the appliance, so that it rotates around its central axis. The greater the reduction in axial velocity of the fluid, the more the amount of energy transferred will be. To prevent energy loss on the sides, as happens in the case of an open hydraulic turbine, the screw cochlea works inside a containment tube. The similarity with the turbine of the ITEG system is clear where the flow in the axial direction collides with the walls of the ducts that wind around the central body causing the rotation of the machine. The efficiency of the turbine largely depends on the inclination of the enveloping ducts which must be sized in such a way that the difference between the energy of the incoming and outgoing fluid is maximum.

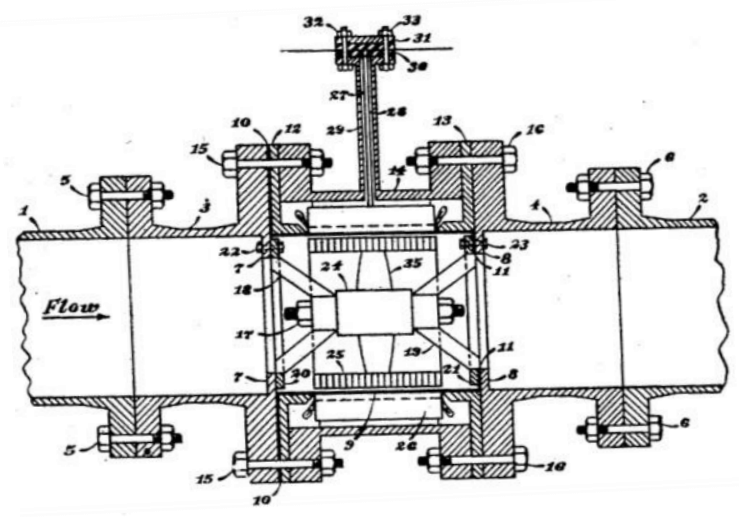

Fig. 19 Patent nr. US2436683A

Patent number US2436683A of Joseph H. Wood [40] present a generator for pipelines providing a mean associated with a pipeline which uses the pressure and flow of the fluid therein to generate electric current which can be utilized to prevent electrolysis in the pipe or for other purposes for which electric energy may be required. As illustrated in fig. 19, the rotor turbine, inserted inside the pipe, is held in position through wires in unspecified material (numbers 18 and 19) and rotates around the shaft (number 17) thanks to the bearings. Permanent magnets 


\section{AJAST}

Asian Journal of Applied Science and Technology

Volume 4, Issue 4, Pages 44-67, October-December 2020

representing the rotor (number 25) are fixed to the ends of the turbine blades, the stator is placed on the outside of the pipe (number 26) and is isolated from the moving fluid through a layer of waterproof material (number 9). The alternating current generated in the stator is then conducted, through the insulated cable (number 28), as suggested in the description of the patent, to the other branch of the pipe (fig. 20) in order to resolve the electrolysis phenomenon.

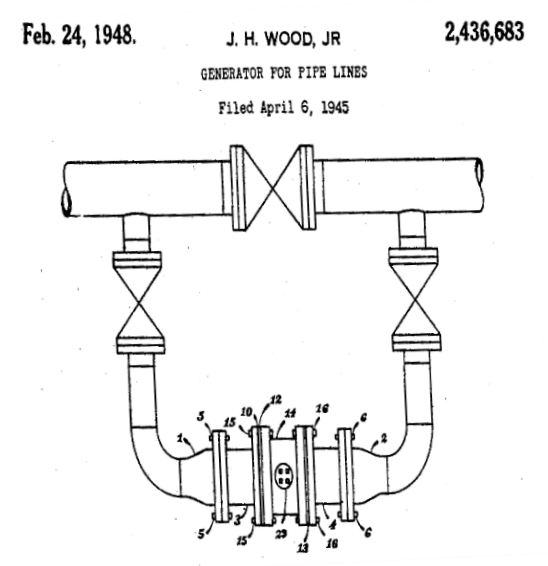

Fig. 20 Patent nr. US2436683A

US patent 3422275A [41], illustrated in fig. 21, has a system like the one previously described. It is a reversible turbine, that is, it can also be used as a centrifugal pump. In this case, the authors of the patent Braikevitch et al. have given greater detail in some parts: in fig. 21 the coupling between rotor and stator is visible, particularly critical as the rotor and the magnetic poles are immersed in the fluid.

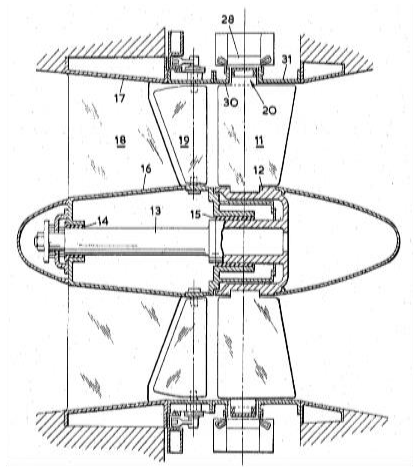

Fig. 21 Patent nr. US3422275A

The poles (number 20) are mounted at the ends of the blades and are made up of different parts: at the base there is a metal ring (number 21), above the coils field (number 24) surround the poles (number 22) and are held in position by polar points (number 25) equipped with countersunk holes in which screws (number 26) that connect the polar points (number 25) to the poles (number 22). The entire pole is then encapsulated in a synthetic resin (number 27) 
to isolate it from the fluid. The stator (number 28) is mounted concentrically to the rotor thanks to the flexible annular joints (number 34) tightened with the screws (number 37) between the rings (numbers 35 and 36) and the radial walls of the pipe (numbers 32 and 33) and it has, on the internal perimeter, a plastic membrane (number 29). More recent studies have been taken into consideration: in particular, those of Stoican (Prisecaru) \& Nicolae Băran about a rotating volumetric pump [16] and a rotary machine that can function as a force machine and as a work machine [18]. It has also been examined the study of Almaslamani [17], which could be considered to increase the fluid flow rate in ITEG.

\section{Results and Discussion}

\section{Mathematical model}

In order to exploit the potential of ITEG, it is necessary to model it by mathematical formulas so as to be able to size it according to the required applications. ITEG can be considered an evolution of the hydraulic screw of Archimedes, also known as the cochlea, made up of a large screw with one or more principles, rotating around a central axis. The lower part is immersed in the liquid or granular material to be lifted. Through the rotation of the screw, a certain amount of material is collected that, for each revolution, advances a distance equal to the screw pitch until, when it reaches the top, it is discharged into a tank or a collection channel. Although it is generally an operating machine as by definition it absorbs energy for carrying out a work, in some applications it can be used as a driving machine and in this case it is known as a screw turbine: the liquid flows into the tube from top to bottom and its downward motion activates the Archimedes screw putting it in rotation and producing kinetic energy that can be collected to generate electric energy. The constructive analogy is between ITEG and an Archimedes' screw with more principles, in which every principle can be associated to a duct of ITEG. At each circular crown there are a variable number of ducts. It can therefore be considered that each circular section corresponds to a screw that does not develop axially but which juxtaposes the principles side by side in a circular arrangement. To define the mathematical model, it has been taken into consideration a rotor whose geometry is made up of circular crowns divided by radial septa, each duct has an isosceles trapezoid shape in which the bases are arcs of circumference and all the ducts have the same pitch $p$.

\section{Useful volume}

The first step is to calculate the volume occupied by the fluid inside the rotor. Looking at the rotor from the front and considering the fluid inlet section, the area occupied by the walls that separate the cavities must be subtracted from the useful section. The starting equation for the volume is:

$V=S * L$

The first term that appears in (1) represents the total useful surface of the rotor, that is, the one that encounters the fluid. To calculate the total useful surface of the rotor, the calculation has been divided for circular crowns. The surface of the circular crown is the total area of the circle with a larger radius minus the area occupied by the circle with a smaller radius. The area of a generic circular crown $\mathrm{j}$ is therefore: 


\section{ANAST}

$A c=\pi\left(R_{j}^{2}-r_{j}^{2}\right)$

where $R_{j}$ is the maximum radius and $r_{j}$ is the minimum radius of the circular crown $j$.

As regards the area occupied by one radial wall, it is necessary to make the difference between the external radius $\mathrm{R}$ and the internal radius $r$ of the rotor and multiply it by the thickness of the walls:

$$
A r=(R-r) * S
$$

Since the rotor has several circular crowns it is enough to repeat the operation for all the sections and to obtain the total useful surface given by:

$S=\pi\left(R^{2}-r^{2}\right)-\left[\sum_{j=1}^{k} \pi\left(R_{j}^{2}-r_{j}^{2}\right)+(R-r) * S * n\right]$

with $\mathrm{k}$ equal to the number of circular crowns and $\mathrm{n}$ equal to the number of radial walls.

As for $\mathrm{L}$ calculation, considering a generic circular crown $\mathrm{j}$, the length $\mathrm{Lj}$ of the duct is given by the formula:

$$
L_{j}=\sqrt{\left(2 \frac{r_{j}+R_{j-1}}{2} \pi\right)^{2}+(m * p)^{2}}
$$

where $\mathrm{m}$ is a coefficient equal to 1 if the length of the rotor is equal to $\mathrm{p}$. By iterating the procedure on all the circular crowns, the relative lengths are calculated. The average value of the lengths of the $L_{j}$ is equal, with good approximation, to the $\mathrm{L}$ value sought. A more precise calculation may be made, but it is beyond the scope of this paper. Therefore, the useful volume of the rotor is:

$V=\left\{\pi\left(R^{2}-r^{2}\right)-\left[\sum_{j=1}^{k} \pi\left(R_{j}^{2}-r_{j}^{2}\right)+(R-r) * S * n\right]\right\} * L$

\section{Flow}

Consider a generic circular crown $\mathrm{j}$, made up of many adjacent ducts, all at the same distance from the rotation axis and a generic duct inside this circular crown: it has a helical shape with a pitch $\mathrm{p}_{\mathrm{j}}$ and it can be assimilated to a Archimedes screw with one principle. The volume of a duct, for a complete pitch $p_{j}$, is equal to $V_{j}$ and imagine that it is filled with the fluid. At each complete turn of the rotor, a volume of fluid equal to $V_{j}$ comes out of the end of the duct. This is intuitive if the length of the rotor is equal to one pitch. For example, if the length of the rotor is half of 1 , at each turn $1 / 2 V_{j}$ will come out twice, that is again $V_{j}$, a result that can be considered valid in general. Considering all the ducts, and setting:

$\mathrm{V}=$ total useful volume, $\mathrm{n}=$ number of revolutions/units of time the flow rate $\mathrm{Q}$ is:

$Q=n * V$

\section{Efficiency}

A fundamental part of the calculation model is the estimation of the machine's efficiency. The efficiency of a turbine or pump is defined as the product of several partial efficiencies (volumetric, mechanical and hydraulic), which concern different technical specifications [19]. The energy losses that occur within a driving machine are of 
a different nature. The hydraulic losses are due to the dissipation of energy following impacts, deviations or section variations that are encountered by the fluid threads during their journey. For the hydraulic machine to perform optimally, when building it, two basic rules must be kept present. The latter are called "hydraulic aphorisms" [19] and their respect and observance allow to obtain acceptable values of hydraulic efficiency: the fluid must enter without impact and exit with the minimum possible speed. The first condition is understandable as each impact dissipates a certain amount of energy at the expense of the useful work produced. The second is justified by the need to use the most part of the kinetic energy possessed by the fluid at the inlet of the rotor. In designing the rotor, these aphorisms were considered to make the hydraulic efficiency as high as possible and so it can be estimated as:

$\eta_{i}=0.95-0.99$

The volumetric losses are constituted by the quantity of liquid which, although it has been processed by the machine, is not conveyed to the delivery pipe because of games or liquid leaks through the sealing elements towards the outside. Most part of the fluid will encounter the useful surface and there will be liquid leaks extremely limited:

$\eta_{v}=0.99$

The mechanical losses are due to the dissipation of energy necessary to overcome the frictions of the components. The mechanical frictions will be practically zero as the rotor "floats" in a magnetic field and, for this reason, it must not overcome the frictions between the bearings and rotor typical of hydraulic machines:

$\eta_{m}=0.99$

The total efficiency of the machine, given by the product of the three partial efficiencies, will therefore be very high and will be in a range between 0.95 and 0.98 .

$\eta=\eta_{v} * \eta_{m} * \eta_{i}$

\section{Powers}

Knowing the flow rate, the total efficiency of the machine and other technical characteristics such as the input and output quota of the fluid, the nature of the latter, the initial and final pressure and the difference in height to be covered, the losses inside the pipes, it is possible to calculate the power of the machine [19]. For pumps or turbines that move or exploit fluids it is necessary to refer to the Bernoulli principle [19], applied to two generic sections of the pipe: "the energy possessed by the fluid in section 2 is equal to the energy it possesses in section 1, less continuous load losses (in the segment of duct between the two sections considered) and accidental losses". Indicating the continuous losses with $\mathrm{Y}$ and with $\sum y$ the sum of the accidental ones, the Bernoulli equation is:

$z_{1}+\frac{p_{1}}{\square}+\frac{v_{1}^{2}}{2 g}-Y-\sum y=z_{2}+\frac{p_{2}}{\square}+\frac{v_{2}^{2}}{2 g}$

where $\mathrm{z}$ is the elevation of the section with respect to a reference plane, $\mathrm{p}$ and $\mathrm{v}$ are the pressure and velocity of the fluid. If there is an exchange of energy with the outside, due to the presence of a hydraulic machine inserted in the section considered, the relationship is modified as follows: 
$z_{1}+\frac{p_{1}}{\square}+\frac{v_{1}^{2}}{2 g}-Y-\sum y \pm L_{i}=z_{2}+\frac{p_{2}}{\square}+\frac{v_{2}^{2}}{2 g}$

The term $L_{i}$ in the first member is the work exchanged with the machine by a weight unit of the flowing fluid. As for the \pm sign, if an operating machine (for example a pump) is inserted between two sections, it is in a position to supply energy to the fluid passing through it and therefore the term $L_{i}$ must be considered positive since the final energy will undoubtedly be greater than the initial one; reasoning in a similar way, the work $L_{i}$ is considered negative when a driving machine is inserted in the section considered which, by absorbing energy from the operating fluid, produces mechanical work. Using ITEG as a turbine, the power P generated is defined as the product of the flow rate multiplied by the net jump $\mathrm{H}$ and the specific weight of the fluid $\gamma$. In case of use of ITEG as a pump, to give the fluid the prevalence $\mathrm{H}$, it is necessary to supply the liquid with the power $\mathrm{P}$ :

$P=Q * H * \gamma$

The calculated power is for an ideal machine, whose efficiency is unitary. ITEG has a very high but not unitary efficiency $\eta$, estimated between 0.95 and 0.98 . By multiplying the power by the efficiency, the useful power is obtained for the use as turbine:

$P_{u}=Q * H * \gamma * \eta$

While, for the use as pump, the absorbed power is obtained by:

$P_{a}=\frac{P}{\eta}$

\section{Speed}

To study how the speed inside the rotor ducts varies, triangles of speed are drawn at the input and at the output of the rotor [19]. It is necessary to do this because, depending on the radial distance of the ducts from the rotation axis, the triangle of speeds is different. The rotor has its own rotation speed and the fluid lapping the surface in turn has its own speed which for simplicity it is assumed to be perpendicular to the useful surface of the rotor. So, the rotor is characterized by a double reference system. The absolute reference describes how the fluid moves from the point of view of a "fixed observer". The second is the relative one that describes how the fluid moves inside the ducts from the point of view of an observer united with the rotor. The known formulas of kinematics state the following vector sum:

$\vec{c}=\vec{v}+\vec{u}$

where:

$\vec{c}$ is the absolute speed

$v$ is the relative speed

$\vec{u}$ is the entrainment speed 


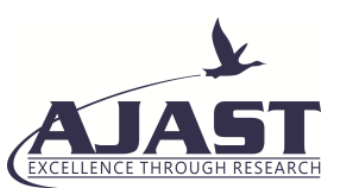

Asian Journal of Applied Science and Technology Volume 4, Issue 4, Pages 44-67, October-December 2020

With reference to fig. 22, it is assumed the black vector as absolute speed c, the green vector is the relative speed that the fluid has inside the ducts, considering a reference system united with the rotor, and the red vector is the entrainment speed, that is the tangential speed of rotation in correspondence of the considered point. As the rotation axis is approached, the inclination of $\mathrm{v}$ decreases as the twisting of the ducts becomes lower. The entrainment speed is linked by the relation $\mathrm{u}=\omega * \mathrm{r}$, where the angular speed $\omega=\frac{2 \pi \mathrm{n}}{60}$, remains constant at every distance $\mathrm{r}$ from the rotation axis. What varies is $\mathrm{u}$, which will increase as the radius increases. Since $\mathrm{c}$ is known and, knowing the number of turns $\mathrm{n}, \mathrm{u}$ and $\omega$, the unknown is $\mathrm{v}$, whose inclination must be parallel to the wall of the duct, in order to satisfy the first hydraulic aphorism.

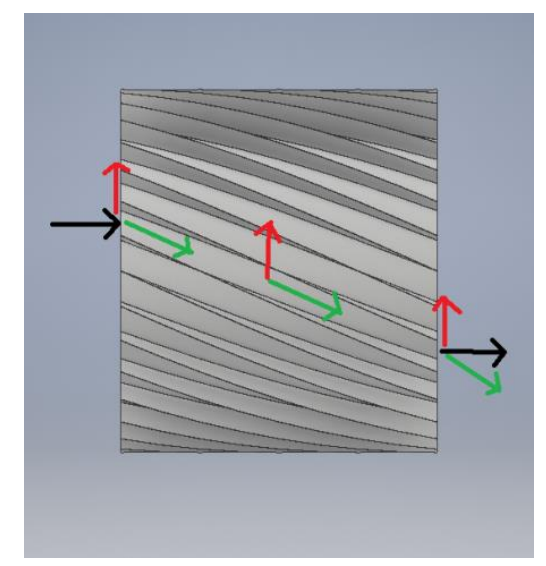

Fig. 22 Speed vectors

A further analysis is carried out on the inclination of the ducts as it decreases approaching the axis of rotation: the innermost shafts will be less inclined than the outermost shafts as the rotor pitch is constant for all levels. To find the angle of inclination $\alpha$ of the duct, indicating with $\mathrm{p}$ the pitch and $\mathrm{d}$ the diameter, it is used the following formula:

$$
\alpha=180-(90+\beta)
$$

where $\beta=\operatorname{arctg}\left(\frac{p}{2 \pi \mathrm{d}}\right)$

It is so possible to draw the speed triangles, fig. 23,24 , in which the subscripts 1 and 2 express respectively the input and output speeds.
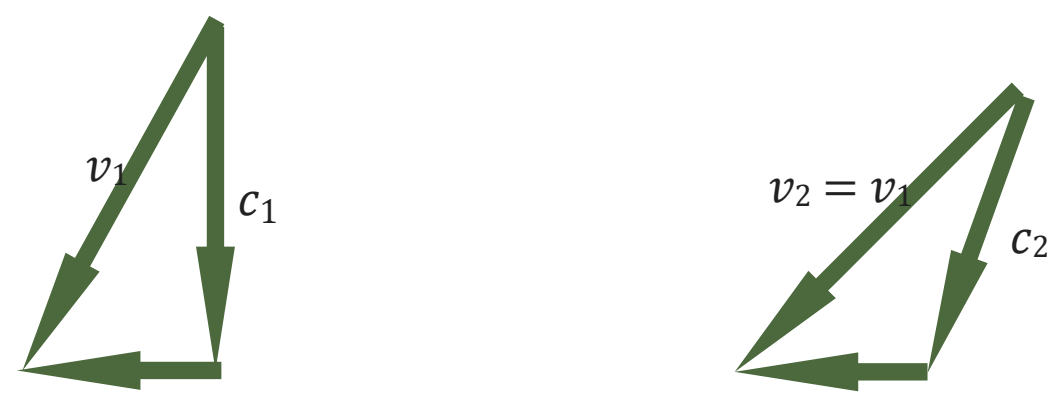

Fig. 23 Triangle of input speeds

Fig. 24 Triangle of output speeds

As the section of the duct is constant, if the slight losses encountered while crossing the ducts (pressure drops) are neglected, the relative exit speed will have the same value in module as the relative entry speed: 
$v_{1}=v_{2}$

The relative input speed vector will be the difference between the absolute fluid and peripheral speed input vectors of the rotor (fig. 23).

$\vec{v}_{1}=\vec{c}_{1}-\overrightarrow{u_{1}}$

Since the rotor is a rigid body, it results that:

$\overrightarrow{u_{1}}=\overrightarrow{u_{2}}$

Considering that the direction of $\vec{v}_{2}$ will be parallel to the duct as in fig. 22, and from the relations (15), (16) and (17), it follows the triangle of the output speeds in fig. 24.

The kinematic energy transferred to the turbine is a function of the difference in absolute speed of the fluid entering and leaving it:

$\Delta E_{\text {fluid }}=\frac{1}{2} \rho V_{\text {fluid }}\left(c_{1}^{2}-c_{2}^{2}\right)$

The choice of a "light" material, in addition to promoting flotation, is an advantage for the transformation of fluid dynamic energy into electrical energy. In fact, the energy of a rotor is directly proportional to its inertia "I" that depends on the mass:

$\Delta E_{\text {fluid }}=E_{I T E G}=\frac{1}{2} I \omega^{2}$

where

$I=\int_{V_{\text {iteg }}} r^{2} d m$

In which $\mathrm{r}$ is the radius, distance of the mass from the rotation axis.

Given that the goal is to have a rotor that rotates as fast as possible, from formula (19) it can be deduced that the angular speed of the magnets is inversely proportional to the inertia of the turbine. Consequently, the lower the mass the faster the rotor will be. The fluid will enter the turbine with a certain absolute speed $c_{1}$ and will leave it with a speed $c_{2}$ lower than the previous. Considering that $\omega$ of the turbine is equal in all its points having the same distance $\alpha$ from the axis of rotation, it follows that the fluid will pass through the turbine with constant speed and in particular this speed will be equal to the relative speed $v$. Following these considerations, it is possible to write the relationship between the angular speed of the rotor $\omega$ and the speed of the fluid coming out the turbine $v_{\text {out }}$ :

$\omega=\frac{v_{\text {out }}}{p}=\frac{v_{\text {out }}}{2 r \pi \tan \alpha}$

Where $\mathrm{p}$ indicates the pitch and $\mathrm{r}$ the radius.

From (21) it is possible to derive the relationship between the speed possessed by the fluid with the peripheral speed of the rotor:

$\mathrm{u}=\mathrm{r} \omega$ 
replacing (21) in (22):

$v_{\text {out }}=2 u \pi \tan \alpha$

The fundamental turbine equation, derived from the Bernoulli principle:

$L_{i}=\frac{c_{1}^{2}-c_{2}^{2}}{2 g}+\frac{v_{2}^{2}-v_{1}^{2}}{2 g}+\frac{u_{1}^{2}-u_{2}^{2}}{2 g}$

expresses, in the most generic way, the hydraulic work developed by a unit weight of operating fluid ( $\mathrm{g}$ is the acceleration of gravity). Considering a generic "circular crown" of ducts, having a constant section, it can be deduced that:

- $\mathrm{v}$ is constant in modulus, for the continuity equation, as the section is constant

- $\mathrm{u}$ is constant, as the distance from the rotation axis is constant

It follows that:

$L_{i}=\frac{c_{1}^{2}-c_{2}^{2}}{2 g}$

The hydraulic work is greater when it's greater the difference in the absolute input and output speeds; in particular, by reducing $c_{2}$, the work developed is increased, in accordance with the second hydraulic aphorism. This reduction in speed involves a free outlet or, if inside a pipe, an increase in the available section or, if the section is constant, an increase of the fluid pressure.

It has been said that ITEG can be assimilated to a set of concentric circular crowns, each consisting of adjacent ducts. These ducts, belonging to the same circular crown, can be schematized as a multi-principle screw. All circular crowns have the same pitch. As a result, the ducts of the circular crowns closest to the rotation axis will have a shorter length than those of the outermost crowns. Since the fluid arrives with the same absolute speed over the entire surface of the rotor, it could be thought that, crossing different lengths, the crossing times would be different, with imbalances in the flow rate. In reality, we must think in terms of relative speeds; moving away from the rotation axis, the rotation speeds $u$ increases (due to the increase in the radius) and therefore, combining vectorially with the absolute speeds $\mathrm{c}$ (all equal) they generate relative speeds $\mathrm{v}$ progressively higher moving towards the outside: the fluid then flows through the external (longer) ducts with higher speeds. This phenomenon leads to a substantial equality of the crossing times of the ducts.

\section{Forces}

Let's consider ITEG in a turbine configuration, with a vertical fluid flow, parallel to the rotation axis. It is possible to describe the interactions between the mass of fluid and the walls of the turbine independently from the thermodynamic, chemical or physical transformations possibly undergone by the fluid; starting from the conservation of momentum or the impulse equation, the relationship (26) is obtained:

$\vec{F}=\frac{\partial}{\partial t} \int_{\Omega_{0}} \rho \vec{v} d \Omega+\int_{S_{1}, S_{2}} \rho \vec{v}(\vec{v} \cdot \vec{n}) d S-\int_{S_{1}, S_{2}} p \vec{n} d S-\int_{S_{1}, S_{2}} \tau \vec{t} d S+\int_{\Omega_{0}} \rho \vec{g} d \Omega$ 


\section{AJAST}

Asian Journal of Applied Science and Technology Volume 4, Issue 4, Pages 44-67, October-December 2020

Where it is:

$\tau$ and $p$ are the modules of the results of the tangential and normal stresses respectively acting on the surface dS with vectors $t$ and $\vec{n}$.

The various terms are analyzed:

$\frac{\partial}{\partial t} \int_{\Omega_{0}} \rho \vec{v} d \Omega$ represents the effect of the inertia of the system on local variations of density and speed over time and is null for permanent speeds.

$\int_{S_{1}, S_{2}} \rho \vec{v}(\vec{v} \cdot \vec{n}) d S$ indicates the flow of the momentum of the fluid through $S_{1}$ and $S_{2}$.

$\int_{S_{1}, S_{2}} \overrightarrow{p n d S}$ represents the thrust that the contour surface exerts on the fluid which is therefore equal and opposite to that which the wall will receive of the fluid.

$\int_{S_{1}, S_{2}} \tau \vec{t} d S$ is the contribution given by the viscous frictions generated by the flow of the fluid on the walls.

$\int_{\Omega_{0}} \rho \vec{g} d \Omega$ represents the weight of the mass of fluid in the volume $\Omega$.

In the hypotheses of steady state and absence of viscous effects, valid with good approximation for machines operating with air or water (as in the case in question), and neglecting the forces of volume, it is possible to write

$\vec{F}=\int_{S_{1}, S_{2}} \rho \vec{v}(\vec{v} \cdot \vec{n}) d S+\int_{S_{1}, S_{2}} p \vec{n} d S$

Considering the flow, in this case, one-dimensional it is obtained:

$\vec{F}=\dot{m}\left(\vec{v}_{1}-\vec{v}_{2}\right)+p_{1} S_{1} \vec{n}_{1}-p_{2} S_{2} \vec{n}_{2}$

with $\overrightarrow{v_{1}}$ and $\overrightarrow{v_{2}}$ the components of the normal speeds are indicated in sections $\mathrm{S} 1$ and $\mathrm{S} 2$ and with $\dot{m}$ the mass flow $(\rho Q)$.

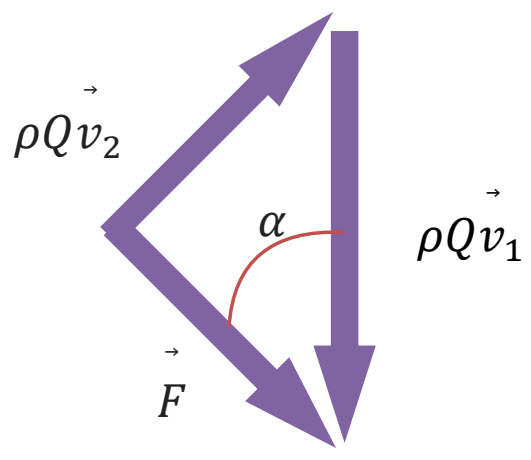

Fig. 25 Vectorial sum to find the force F 


\section{AJAST}

Asian Journal of Applied Science and Technology Volume 4, Issue 4, Pages 44-67, October-December 2020

It has been observed that the fluid enters the turbine ducts with speed $\vec{v}_{1}$ in the vertical direction and collides the wall of the duct inclined at an angle $\alpha$ with respect to the horizontal, considering the zero pressure difference $\left(p_{1}-p_{2}=0\right)$, the relation $(25)$, can be written as:

$\vec{F}=\dot{m}\left(\vec{v}_{1}-\vec{v}_{2}\right)$

The force $F$ (fig. 25) represents the thrust that the wall of the turbine duct impresses on the fluid and is equal and opposite to that which it will undergo.

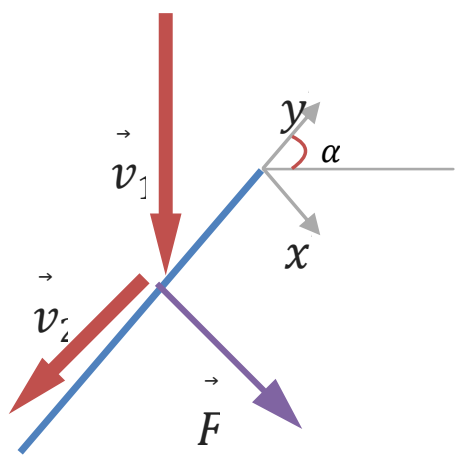

Fig. 26 - Force generated by the collision of the fluid against the wall of a turbine duct

This force can be divided into two components: one long $x^{\prime}$ (orthogonal to the wall of the duct) and one long $y^{\prime}$ (parallel to the duct) as shown in fig. 26. If the wall were fixed, the velocity $\vec{v}_{1}$ would deviate in $\vec{v}_{2}$ parallel to the duct as it would slide along it.

Therefore:

$\vec{F}=\dot{m}\left(\vec{v}_{1}-\vec{v}_{2}\right)=\dot{m}\left(\vec{v}_{1}+\left(-\vec{v}_{2}\right)\right)$

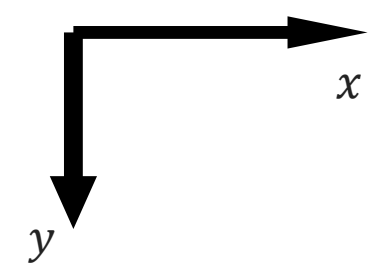

Fig.27 Reference axes

Since the frictions between fluid and wall are neglected, there will be no forces in the direction of the latter, consequently the thrust that the wall undergoes is directed orthogonally to it.

$\overrightarrow{F_{y^{\prime}}}=0$

$\vec{F}=\vec{F}_{x^{\prime}}=\rho Q v_{1} \cos \alpha$

In the hypothesized configuration, and by suitably shaping the pipe in which the rotor is housed, an effect of self-floating of the rotor itself could be obtained. To make the turbine float, the sum of the forces directed along the 


\section{A TAST}

Asian Journal of Applied Science and Technology

Volume 4, Issue 4, Pages 44-67, October-December 2020

$\mathrm{y}$ axis (reference to the axes in fig. 27) must be zero $\left(F_{y}-F_{g}+F_{P}=0\right)$. This condition depends on the volume of the internal hollow cylinder and the weight of the turbine itself. In order to minimize the latter, the choice of material of which the turbine will be made must fall on materials with a very low specific weight. For this reason, plastics are excellent candidates which, in addition to having an average density of less than $1 \mathrm{~kg} / \mathrm{dm}^{3}$, are used by 3D printers, which represent a precise and effective method of producing the turbine.

$\overrightarrow{F_{g}}=V_{\text {iteg }} \rho g=S_{\text {iteg }} h_{\text {iteg }} \rho g$

$\vec{F}_{P}=V_{\text {iteg }} \rho_{\text {iteg }} g=S_{\text {iteg }} h_{\text {iteg }} \rho_{\text {iteg }} g$

where

$h=p n=\pi D_{\text {est }}(\tan \alpha) n$

n number of turns of the windings

$\mathrm{p}$ pitch of the windings

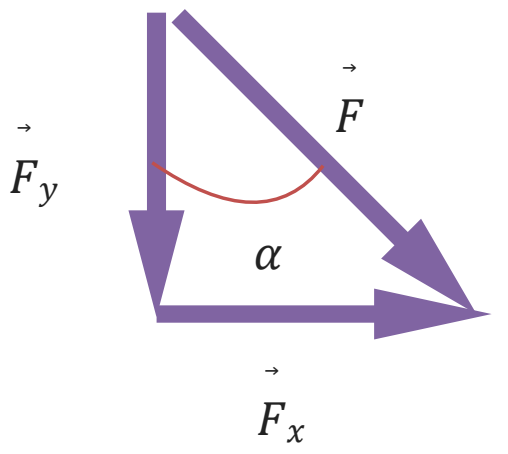

Fig. 28 Decomposition of $F$

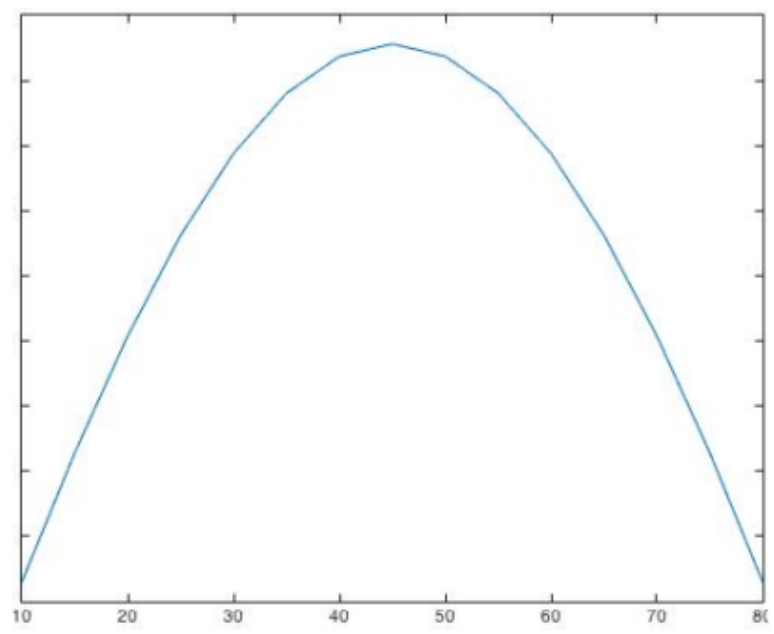

Fig. 29 Graph of the trend of the force in the $\mathrm{x}$ direction as the angle of inclination of the turbine pipes changes 


\section{AUAST}

Asian Journal of Applied Science and Technology Volume 4, Issue 4, Pages 44-67, October-December 2020

So, it is obtained:

$\overrightarrow{F_{g}}=S_{\text {int }} \pi D_{\text {est }}(\tan ) n \rho g$

As can be understood from the decomposition of $F$ in fig. 28 .

$\overrightarrow{F_{y}}=\rho Q v_{1} \cos ^{2} \alpha$

The thrust in the $\mathrm{x}$ direction is responsible for the rotation of the turbine as it is orthogonal to the axis of rotation:

$\overrightarrow{F_{x}}=\rho Q v_{1} \cos \sin \alpha$

Since the direct force along $\mathrm{x}$ is responsible for the rotation of the turbine, and the angular velocity of this increases with the increase of the force in question, it is of interest to find the inclination of the rotor pipes that maximizes the thrust in this direction. By deriving the (38) with respect to the angle $\alpha$ and equaling it to zero, it is possible to find the value of $\alpha$ for which the force $F_{x}$ is maximum:

$\frac{\delta F_{x}}{\delta \alpha}=0 \quad \rho Q v_{1} \cos (2 \alpha)=0$

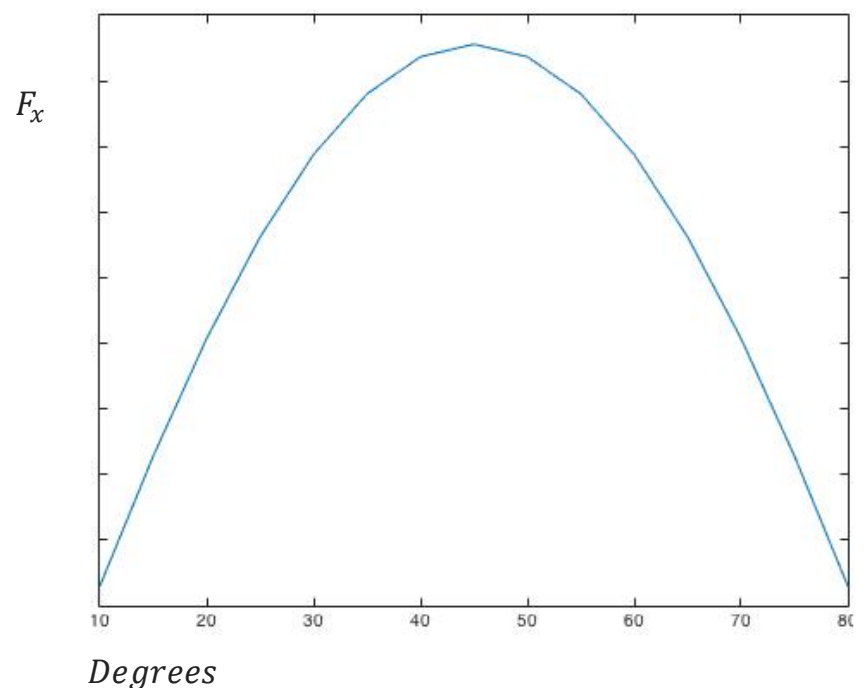

Fig. 30 Graph of the trend of in the $x$ direction as the angle of inclination of the turbine pipes changes

From the derivative (39), and from the representation in graph of (38) in fig. 29, it is possible to deduce that $F_{x}$ is maximum for $\alpha=45^{\circ}$.

\section{Conclusions}

The paper has presented an innovative fluid machine having a dual function, as it can be used as pump and as turbine. The rotor is the cylindrical component that plays a fundamental role in ITEG. It represents the rotating component of the machine whose purpose is to intercept the fluid that laps against its own useful surface. The rotor, in the "pump" configuration, gives energy to the fluid or, in the "turbine" configuration, transforms the kinetic energy possessed by the fluid into mechanical (rotational) energy. In all the examples treated in the literature 
Asian Journal of Applied Science and Technology Volume 4, Issue 4, Pages 44-67, October-December 2020

review, the turbines / generator are kept in axis with the help of bearings that, although significantly reduced in number, compared to systems in which the generator is not integrated in the turbine, still represent a critical components, especially if they are placed in contact with fluids that deteriorate them prematurely. There are already on the market various turbine systems integrated in the pipes for a multitude of cases of application, but all cases present substantial differences compared to ITEG. It has, in fact, the advantageous peculiarity of being completely free of mechanical bearings. The correct position of the rotor is assured by magnetic bearings, friction-free, in favor of efficiency. Moreover, it is thinkable to design a rotor that, in specific conditions, is able to float in the fluid, in "self-floating". Therefore, the ITEG efficiency remains constant and always equal to very high values and this confirms the fact that, also due to variations in the flow that can occur during the course of the year along a river or course of water, the machine will work maintaining a high efficiency. Ultimately, ITEG is characterized by a perfect symmetricity (reversible axial action), reduced turbulence (thanks to the high resolution of the helical grooves), no need for axial mechanical supports (bearings or thrust bearings) and a high structural resistance (given by the implicit tension-structure and therefore less bending / deformation with respect to bending / twisting in the blades), that make it unique.

\section{Patents}

Farné S., Lavanga V., ITEG - ITEG - INTEGRATED TURBINE ELECTRIC GENERATOR - ITALY PATENT NR. N. 102018000011105 of 12/11/2020 registered at UIBM Rome (Italy) - International Application No. PCT/IT2018/000164 - Publication Number WO/2019/116406 - Publication Date 20.06.2019 - ITEG.

Acknowledgments: Dr. Vito Lavanga, freelance researcher and inventor.

\footnotetext{
References

Journal Articles

1. Stergiopoulou, A.; Stergiopoulos, V. Archimedes in Cephalonia and in Euripus Strait: Modern Horizontal Archimedean Screw Turbines for Recovering Marine Power. Journal of Engineering Science and Technology 2013, Review 6 (1), $44-51$

2. Stergiopoulou A.; Stergiopoulos V. Quo Vadis Archimedean Turbines Nowadays in Greece, in the Era of Transition. Journal of Environmental Science and Engineering 2012, A 1, 499-509

3. Stergiopoulou A.; Stergiopoulos V. Back to the Future: Rediscovering the Archimedean Screws as Modern Turbines for Harnessing Greek Small Hydropower Potential. Fresenius Environmental Bulletin 2013, PSP Volume 22 - No 7a, 2053- 2058

4. Stergiopoulou A.; Stergiopoulos V. Archimedes in Cephalonia and in Euripus Strait: Modern Horizontal Archimedean Screw Turbines for Recovering Marine Power. Journal of Engineering Science and Technology Review 2013, 6 (1), 44 -51

5. Stergiopoulou A.; Kalkani E. Towards a C.F.D. Study of Innovative Archimedean Inclined Axis Hydropower Turbines. International Journal of Engineering Research \& Technology 2013, 2 (9), 193-199
} 
Asian Journal of Applied Science and Technology

Volume 4, Issue 4, Pages 44-67, October-December 2020

6. Stergiopoulou A.; Kalkani E. Investigating the Hydrodynamic Behavior of Innovative Archimedean Hydropower Turbines. International Journal of Research and Reviews in Applied Sci. 2013, Volume 17, Issue 1

7. Casini M. Harvesting energy from in-pipe hydro systems at urban and building scale. International Journal of Smart Grid and Clean Energy 2015, vol. 4, no. 4, 316-327

8. Sinagra M.; Sammartano V.; Aricò C.; Collura A.; Tucciarelli T. Cross-flow Turbine Design for Variable Operating Conditions. Procedia Engineering 2014, Volume 70, 1539-1548

9. Raza A.; Mian M.S.; Saleem Y. Modeling of Archimedes Turbine for low head hydro power plant in Simulink MATLAB. International Journal of Engineering Research \&Technology 2013, 2 (7), 2471-2477.

10. Nuernbergk D.; Rorres C. An Analytical Model for the Water Inflow of an Archimedes Screw Used in Hydropower Generation. ASCE Journal of Hydraulic Engineering 2013, Vol. 139, Issue 2, 213-220

11. Fiardi E. Preliminary Design Preliminary design of Archimedean Screw Turbine Prototype for Remote Area Power Supply. Journal of Ocean, Mechanical and Aerospace 2014, 5, 30-33

12. Müller G.; Senior J. Simplified theory of Archimedean Screws. J. of Hydraulic Res. 2009, 47 (5), 666-669.

13. Rorres C. The turn of the Screw: Optimal Design screw: optimal design of an Archimedes Screw. Journal of Hydraulic Engineering 2000, 126 (1), 72-80

14. Shimomura M.; Takano M. Modeling and performance analysis of Archimedes screw hydro turbine using moving particle semi-implicit method. Journal of Computational Science and Technology 2014, 338-353

15. Sobczyk T.; Wegiel T., Grahl-Madsen M., Styrylski M. Integrated turbine with PM generator for small hydro-power plants. Technical Transaction Politechniki Krakowskiej 2010, Issue 17, 99-111

16. Mariana Mirela Stoican (Prisecaru) \& Nicolae Băran. Rotating Volumetric Pump for Wastewater Conveyance. Asian Journal of Applied Science and Technology (AJAST). 2019, Volume 3, Issue 4, Pages 194-198

17. Ammar Fadhil Shnawa Almaslamani. Researches on the Influence of Geometric and Functional Parameters on the Flow Rate of a Rotating Machine with Profiled Rotors. Asian Journal of Applied Science and Technology (AJAST) 2020, Volume 4, Issue 1, Pages 120-126

18. Mariana Mirela Stoican (Prisecaru) \& Nicolae Băran. A Constructive Solution that Can Function As a Force Machine or As a Work Machine. Asian Journal of Applied Science and Technology (AJAST) 2020, Volume 4, Issue 2, Pages 97-107, April-June 2020

Books

19. Farné S. Macchine. Macchine idrauliche, 1st ed.; Collana Synopsis, Casa editrice Medea: Pavia, Italy

20. Nagel. Archimedean screw pump handbook, 1968, RITZ-Pumpenfabrik OHG: Nurnberg, Germany.

21. European Small Hydropower Association. A Layman's Guidebook on How to Develop a Small Hydro Site. 1998, ESHA 


\section{Conference Proceedings:}

22. Stergiopoulou A.; Stergiopoulos V.; Kalkani E. An Eagle 's CFD view of studying innovative Archimedean Screw Renewable Hydraulic Energy Systems. Proceedings of the 4th International Conference on Environmental Management, Engineering, Planning and Economics (CEMEPE) and SECOTOX Conference, Mykonos, 2013, 454-459

23. Stergiopoulou A.; Stergiopoulos V. From the old Archimedean Screw Pumps to the new Archimedean Screw Turbines for Hydropower Production in Greece. Proceedings of the 2nd International Conference on Environmental Management, Engineering, Planning \& Economics (CEMEPE 2009), Mykonos, 2009

24. Stergiopoulou A.; Stergiopoulos V.; Kalkani E. A brief Archimedean history: from ancient spiral screws to modern Archimedean hydropower energy tools, Proceedings of the eRA-5 International Conference, Athens, 2010 25. Stergiopoulou A.; Stergiopoulos V.; Kalkani E. Back to the Future: Rediscovering the Archimedean Screws. Proceedings of the Third International Conference on Environmental Management, Engineering, Planning and Economics (CEMEPE 2011) \& SECOTOX Conference, Skiathos, 2011

26. Stergiopoulou A.; Stergiopoulos V. The paradox of coastal cross flow in Cephalonia island. Proceedings of the 6th International Symposium on Environmental Hydraulics, Athens, 2010

27. Stergiopoulou A.; Stergiopoulos V. From the old Archimedean Screw Pumps to the new Archimedean Screw Turbines for Hydropower Production in Greece. Proceedings of SECOTOX and CEMEPE Conf., Mykonos, 2009 28. Stergiopoulou A.; Stergiopoulos V. Return of Archimedes: Harnessing with new Archimedean spirals the hydraulic potential of the Greek watercourses. Proceedings of the Conference for Climate Change-Sustainable development and Renewable Energy Sources, Thessaloniki, 2009.

29. Stergiopoulou A.; Kalkani E. Investigation of the hydrodynamic behaviour of innovative cochlear turbines. Proceedings of the 12th EYE and 8th EEDYP Conference, Patras, 2012.

30. Stergiopoulos A.; Stergiopoulou V.; Kalkani E. Quo Vadis Archimedes Nowadays in Greece? Towards Modern Archimedean Turbines for Recovering Greek Small Hydropower Potential. Proceedings of the 3rd International Scientific "Energy and Climate Change" Conference, Athens, 2010

31. Stergiopoulou A.; Stergiopoulos V. Greece in the Era of Transition: Archimedean Soft Small Hydropower Development Terra Incognita. Proceedings of 5th International CEST2013_0196 Conference Protection and Restoration of the Environment XI, Thessaloniki, 2012, 1429-1438

32. Stergiopoulou A. et al. Towards Horizontal-Axis Archimedean Kinetic Energy Conversion Systems in Cephalonia and in Euripus Strait. Proceedings of International Conference IC-SCCE, Athens, 2012, 468-475

33. Stergiopoulou A.; Stergiopoulos V.; Tsivolas D.I.; Stylianou A.S. Two innovative experimental Archimedean Screw Energy Models in the Shadow of Archimedes. Proceedings of the 5th International Conference on Experiments / Process / System Modeling / Simulation / Optimization, Athens, 2013 
34. Stergiopoulou A., Stergiopoulos V., Kalkani E. et al. Towards a first C.F.D. Study of Innovative Archimedean Kinetic Energy Conversion Systems in Greece. Proceedings of the 5th IC-EpsMsO, 2013, 634-640

35. Williamson S. J.; Stark B. H.; Booker J. D. Low Head Pico Hydro Turbine Selection using a Multi-Criteria Analysis. World Renewable Energy Congress, 2011, 44(0), 1377-1385.

36. Koetsier T.; Blauwendraat H. The Archimedean Screw-Pump: a note on its invention and the development of the theory. Proceedings of the international symposium on history of machines and mechanisms, 2004, vol. 5, $181-94$

37. Lyons M.; Lubitz W.D. Archimedes Screws for micro hydro power generation. Proceedings of the ASME 7th International Conference on Energy Sustainability \& 11th Fuel Cell Science,2013

38. M.W.K. Lyons, "Lab Testing Lab testing and Modeling of Archimedes Screw Turbines," Archimedes screw turbines, 2014, University of Guelph; Guelph.

\section{Patents}

39. Rosefsky J.B. (2003), Ribbon drive power generation for variable flow conditions, Patent number: US 6626638, https://patents.justia.com/patent/6626638;

40. Wood J. H. (1945), Generator for pipelines, Patent number: US2436683A, https://patents.google.com/ patent/US2436683A/en

41. Michael Braikevitch M; Bruce D. A. Water turbines, pumps and reversible pump turbines, Patent number: US3422275A, https://patents.google.com/patent/US3422275A/en 